\title{
A EDUCAÇÃO CONTINUADA DOS ALUNOS EGRESSOS: COMPROMISSO DA UNIVERSIDADE?
}

\author{
THE CONTINUED EDUCATION OF EGRESSED STUDENTS: IS IT A COMMITMENT OF THE \\ UNIVERSITY?
}

\section{LA EDUCACIÓN CONTINUADA DE LOS ALUMNOS EGRESOS: ¿COMPROMISO DE LA UNIVERSIDAD?}

\author{
Vânia Marli Schubert Backes ${ }^{1}$ \\ Elisabeta Albertina Nietsche ${ }^{2}$ \\ Silviamar Camponogara ${ }^{3}$ \\ Rosana da Silva Fraga ${ }^{4}$ \\ Rita de Cássia Cerezer ${ }^{5}$
}

\begin{abstract}
RESUMO: Objetivamos, com esta reflexão teórica, tecer algumas considerações acerca da importância da Universidade, enquanto instituição formadora, no sentido de fomentar um processo educativo que remeta os indivíduos à consciência do inacabamento, segundo referencial de Paulo Freire, e, por conseguinte, ao relevante papel da educação/formação continuada, durante e após a formação acadêmica. Para isso, torna-se imprescindivel resgatar e apontar como metas a integração ensino, pesquisa e extensão, bem como a construção de uma cultura institucional comprometida com a educação continuada e a formação de parcerias e núcleos de apoio ao aluno egresso, como forma de concretizar o compromisso da universidade com a educação continuada dos alunos egressos.
\end{abstract}

PALAVRAS-CHAVE: ensino de enfermagem, ensino-serviço, educação continuada, universidade

ABSTRACT: The objective of this study is to reflect on the role of the university as a fomenter of continued education, during and after undergraduation, according to the referential of Paulo Freire. Thus, it is necessary to rescue and indicate as a goal the integration of teaching, research and extension, as well as the construction of an institutional culture committed to continued education and the development of partnerships and support group for egressed students.

KEYWORDS: nursing education, education-service integration, continued education, university

RESUMEN: Pretendemos con esta reflexión teórica tejer algunas consideraciones sobre la importancia de la Universidad, mientras institución formadora, en el sentido de fomentar un proceso educativo que remita a los individuos a la conciencia del inacabamiento, según referencial de Paulo Freyre y, por consiguiente, al relevante papel de la educación/formación continuada, durante y después de la formación académica. Para ello, es imprescindible rescatar y apuntar como metas la integración enseñanza, investigación y extensión, así como la construcción de una cultura institucional comprometida con la educación continuada y la formación de grupos y núcleos de apoyo al alumno egreso, como forma de concretar el compromiso de la universidad con la educación continuada de los alumnos egresos.

PALABRAS CLAVE: enseñanza de enfermería, integración enseñanza-servicio, educación continuada, universidad

Recebido em 31/01/2002

Aprovado em 26/06/2002

\footnotetext{
${ }^{1}$ Doutora em Enfermagem. Professora Adjunta do Departamento de Enfermagem da UFSM-RS. Coordenadora do GEPES/ UFSM. Pesquisadora da FAPERGS e CNPq.

2 Doutora em Enfermagem. Professora Adjunta do Departamento de Enfermagem da UFSM-RS. Pesquisadora da FAPERGS.

${ }^{3}$ Mestre em Enfermagem. Professora Assistente do Departamento de Enfermagem da UFSM-RS.

${ }^{4}$ Enfermeira Membro do GEPES/UFSM.

${ }^{5}$ Acadêmica de Enfermagem $7^{\circ}$ Semestre da UFSM-RS. Bolsista de trabalho do HUSM.
} 


\section{INTRODUÇÃO}

O homem, sem dúvida, é um ser que busca constantemente crescimento e aperfeiçoamento. Não fosse isso verdadeiro, não estariamos vivenciando tamanho progresso científico, cultural, social. Nos dias de hoje, essa busca por conhecimento parece intensificar-se cada vez mais, visto estarmos vivendo um periodo de intensa explosão tecnológica e globalizante.

No entanto, a conquista do conhecimento precisa acompanhar algumas etapas formais, que passam pela escolarização em nível fundamental, médio e pela formação profissional, que encontra lugar na Universidade. É na Universidade que o individuo encontra terreno fértil para desenvolver e aprimorar valores relacionados à sua vida profissional e pessoal. Neste meio, através da busca do conhecimento científico, também deve encontrar condições para o desenvolvimento da consciência crítica e do seu papel enquanto cidadão. Esses quesitos são essenciais para uma formação profissional que resulte em comprometimento com a sociedade em que está inserido.

Não obstante, torna-se importante destacar que esse processo de formação não deve se encerrar no momento de conclusão de um curso de profissionalização, mas deve continuar por toda a vida do individuo. Essa perspectiva deve surgir no bojo da formação profissional, através do afloramento de valores que permitam ao individuo refletir sobre seu papel enquanto cidadão, comprometido com a sua comunidade e sociedade.

Há que se pensar, porém, qual seria o compromisso da Universidade com a educação continuada dos egressos, no sentido de viabilizar este processo de formação continuada. Tendo por base tal questionamento, o presente estudo objetiva refletir sobre esta temática, encontrando sustentação teórica em Freire (1999) e também apoio nos estudos e vivências obtidos junto ao Grupo de Pesquisa de Educação em Enfermagem e Saúde - GEPES da Universidade Federal de Santa Maria - UFSM/RS na Linha de pesquisa: Educação, Enfermagem e Saúde. Inicialmente, procuraremos fundamentar o estudo com alguns conceitos e reflexões, para, posteriormente, apontar algumas estratégias de ação com vistas a despertar para a necessidade de se investir, já na formação universitária, em educação continuada.

Neste sentido, cabe destacar que a Lei n 9.394/ 1996, que estabelece as Diretrizes e Bases da Educação Brasileira, referida por Santos et al. (1997), também faz referência à Educação Continuada, evidenciando, nos Artigos 40 e 80 , o seguinte:

Art. 40 - A educação profissional será desenvolvida em articulação com o ensino regular ou por diferentes estratégias de educação continuada, em instituições especializadas ou no ambiente de trabalho.

Art. 80 - O Poder Público incentivará o desenvolvimento e a veiculação de programas [...], em todos os niveis e modalidades de ensino, e de educação continuada.

Estas considerações vêm fortalecer ainda mais a importância de estimular novos desafios, estudos e vivências, em relação ao processo de educação continuada na construção de sujeitos comprometidos com a qualidade de vida própria e coletiva.

\section{COMPROMISSO DA UNIVERSIDADE COM A EDUCAÇÃO CONTINUADA: UM CONVITE À REFLEXÃO}

Embora seja um conceito antigo, somente na atualidade o conceito de Educação Continuada tem sofrido as reformulações compativeis com seu real valor para a sociedade moderna e pós-modema. Enquanto, antigamente, a Educação Continuada estava atrelada a um mero processo de aperfeiçoamento técnico-profissional, atualmente já vem sendo entendida como um processo mais amplo.

Segundo Backes et al. (2000, p. 9), a Educação Continuada refere-se a

um processo educativo formal ou informal, dinâmico, dialógico e contínuo, de revitalização pessoal e profissional, de modo individual e coletivo, buscando qualificação, postura ética, exercício da cidadania, conscientização, reafirmação ou reformulação de valores, construindo relações integradoras entre os sujeitos envolvidos, para uma práxis crítica e criadora.

Esta forma abrangente de entender o processo de Educação Continuada acreditamos vir ao encontro dos anseios da sociedade, que vive a era da globalização e da revolução da informática, atrelada a graves problemas de ordem social e econômico. Sob esta ótica, a Educação Continuada não pode estar relacionada somente ao aperfeiçoamento técnico, mas também a uma constante reflexão de valores, dentro de um contexto coletivo.

Cabe ressaltar, entretanto, que esta visão ainda necessita ser internalizada pelas pessoas e instituições. No que se refere à Universidade, analisando o contexto atual, percebe-se que ela pode não estar satisfazendo as expectativas da opinião pública, por isso torna-se necessária a reflexão sobre seu verdadeiro papel, no contexto histórico em que está inserida. Segundo Penna (1993, p.164), durante muito tempo a universidade brasileira "exerceu um papel de mera formadora de mão-de-obra especializada e quase exclusivamente voltada para o ensino". Apesar dos avanços das atividades de extensão e da ampliação da sua autonomia, em muitos casos há um relativo isolamento dos Centros Universitários, limitados às suas construções e alheios às mudanças no quadro político, econômico, social e institucional do país. Somando-se a isso, reforça Penna (1993, p.165), "determinados veículos de comunicação promovem campanhas insufladoras levando ao conhecimento da opinião pública, uma avaliação distorcida sobre a Universidade Pública e sua função social".

No entanto, independentemente do País e do contexto histórico em que a universidade está inserida, há um elo comum a todas, materializado na relação estabelecida entre a compreensão da universidade enquanto centro de conhecimento e de preparação do homem e sua inserção social. Ainda de acordo com Penna (1993), nos diferentes momentos históricos, a universidade se coloca como instituição voltada para o conhecimento, visto ora como produto acabado (apenas transmitido, repassado), ora como processo que requer a participação de todos os sujeitos.

Diante disso, concordamos com Penna (1993, p.166) quando diz ser necessário que a Universidade brasileira retome sua finalidade maior que é a de ser um centro de 
reflexão permanente, onde a produção de novos conhecimentos se realize em consonância com as demandas sociais e por meio de um processo interativo que privilegie sua relação com a sociedade civil.

Segundo Faria (2000), a maior parte da produção brasileira em ciência representa muito pouco para o mundo e importamos quase toda tecnologia de que dispomos, o que leva grande parte do nosso Produto Intemo Bruto-PIB. Concordamos com a autora quando refere que as universidades brasileiras encontram neste ponto o seu maior desafio, pelo fato de ser nelas produzida quase que a totalidade da ciência e que, sem um projeto de identificação comprometido com o social, a ciência não chegará a ter uma tecnologia libertadora. Neste contexto, emerge a importância da extensão universitária, colocando a universidade solidária com a sociedade.

Na tentativa de convergir para este intento, a partir de 1968, de acordo com Fernandes (1994), a Reforma Universitária vem enfatizar a necessidade da indissociabilidade entre ensino, pesquisa e extensão, não como uma composição compartimentada, mas realmente como uma ação que visasse formar o homem para atuar em plena consonância com a sua realidade de forma crítica e transformadora.

Esta tentativa logrou alguns resultados positivos para o contexto Universidade/Sociedade, mas notamos que ainda existem algumas lacunas a serem preenchidas, as quais poderiam resultar em maior potencial crítico, criativo e transformador. Neste aspecto, em particular, a Educação Continuada poderia contribuir sobremaneira, visto ser um processo que remete primeiramente a uma revisitação intema de valores, com posterior reflexo no nivel profissional.

Acreditamos que o compromisso do profissional com a sociedade se dá no mesmo nivel do compromisso consigo mesmo. Neste sentido, Freire (1999, p.20) relata que "como homem, que não pode estar fora de um contexto histórico-social em cujas relações constrói seu eu é um ser autenticamente comprometido, falsamente comprometido ou impedido de se comprometer verdadeiramente", ou seja, o profissional age de acordo com a grande maioria, comportase como mero receptor e executor de ordens impostas por uma minoria, por não ter a consciência da necessidade de ser verdadeiramente comprometido consigo e com os outros, ou o profissional se toma comprometido com as questões do seu dia-a-dia, transformando a realidade.

Freire (1999, p.21) nos diz que o profissional não deve julgar-se

\footnotetext{
...habitante de um mundo estranho, mundo de técnicas, e especialistas salvadores dos demais, donos da verdade, proprietários do saber que devem ser doados aos ignorantes e incapazes. Habitantes de um gueto, de onde saiu messianicamente para salvar os perdidos, que estão fora.
}

O profissional que assim se comporta não está se comprometendo verdadeiramente, nem como profissional nem como homem, simplesmente está se alienando. Considerando a Universidade como instituição formadora de profissionais e um centro de "concentração do saber", ela deve estar também comprometida com os profissionais que forma, pois, como diz Freire (1999, p.21), "não é possível um compromisso autêntico se, àquele que se julga comprometido, na realidade se apresenta como algo dado; estatístico e imutável, [...], se percebe a realidade enclausurada em departamentos estanques". Portanto, não podemos ter uma Universidade realmente comprometida com a sociedade e com os seus ex-alunos, parte integrante desta, se a Instituição não vê e não capta a realidade como uma totalidade, cujas partes se encontram em constante interação. Uma Universidade comprometida com a realidade não pode focalizar suas ações sobre partes isoladas desta, mas sim deve direcioná-las para transformar a totalidade (sociedade, país). Isto é, se o que desejamos são profissionais comprometidos em suas profissões e com a sociedade, devemos atuar no sentido de transformar a Universidade em um centro realmente comprometido com a formação do profissional para atuar e intervir criadoramente no mercado de trabalho e no mundo. Esse compromisso deve se dar tanto no âmbito universitário, enquanto alunos, como também após sua graduação. Como salienta Freire (1999, p.21), "o compromisso não pode ser um ato passivo, mas práxis-ação e reflexão sobre a realidade". Continua o mesmo autor, referindo que inserida

...no compromisso do profissional, seja ele quem for, está a exigência de seu constante aperfeiçoamento, de superação do especialismo [...], o profissional deve ir ampliando seus conhecimentos em torno do homem, de sua forma de estar sendo no mundo, substituindo por uma visão crítica a visão ingênua da realidade Freire (1999, p.21).

Assim sendo, não podemos esperar profissionais comprometidos com o desenvolvimento de uma sociedade ou nação, se não lhes foi proporcionado, pela instituição formadora, subsidios para o desenvolvimento de uma visão crítica, do contexto histórico-social em que está inserido. Neste aspecto, deve-se esperar da Universidade o compromisso em não reduzir o aluno ao tecnicismo, a um “autômato manipulável".

Não obstante, a construção do conhecimento, tanto em uma instituição como individualmente, tem um caráter político ligado a interesses sociais e pessoais. O papel da universidade nesse contexto se estabelece à medida que vai "formando" o profissional, de modo a conduzi-lo ao desnudamento crítico da realidade em que está inserido, despertando-Ihe a responsabilidade e o compromisso com as questões sociais. Isso pode ser adquirido através do desenvolvimento de atividades integradas de ensino, pesquisa e extensão, levando à formação profissional caracterizada pela construção de uma dimensão política e crítica da realidade onde vai atuar, interligando o ensino, através da produção de novos conhecimentos, que deverão dar respostas coerentes e adequadas às necessidades sociais. De acordo com Tavares (2000), a concepção de uma universidade voltada para atender os interesses da população, buscando diminuir a desigualdade social existente por meio da democratização do conhecimento elaborado e transmitido pela universidade, torna necessária a explicitação da extensão universitária junto ao ensino e à pesquisa.

Assim, a universidade deve cumprir seu papel de centro produtor e difusor de ciência, tecnologia e cultura, sendo um elemento de extrema relevância para a construção da cidadania.

Ainda segundo Tavares (2000, p. 7), 
...a compreensão da natureza pública da universidade se confirmará na proporção em que diferentes setores da população brasileira usufruam os resultados produzidos pela atividade acadêmica, e isso se dará, na medida em que a universidade passa a ter 'a cara de sociedade'. Isto é, em outros termos, quando a sua preocupação com os problemas sociais se torne visivel nas salas de aula, nos laboratórios e nas atividades extramuros.

A Universidade, então, não pode se furtar ao papel de proporcionar ao aluno a oportunidade de desenvolver esta consciência crítica. A Educação Continuada, iniciada já na formação acadêmica, é o meio ideal de assegurar o desenvolvimento integral do profissional que traga, como conseqüência, o comprometimento com o seu meio, com a sociedade em que vive.

Neste sentido, Penna (1993, p.195) complementa

que

\begin{abstract}
...a Universidade deve ser dos sábios, mas também dos cidadãos, com isso a produção universitária tenderá a ser coletiva, não haverá mais o sábio isolado responsável por uma matriz do pensamento, mas sábios que por intermédio de uma comunidade científica, possam fundar correntes e concepções originais.
\end{abstract}

Ao partilhar suas informações, a Universidade e exalunos adquirem um grau de maior responsabilidade frente aos problemas sociais, econômicos, culturais, entre outros, enfrentados por ambos, desenvolvendo-se uma cumplicidade que se refletirá numa valorização da Universidade por parte da sociedade, que passa, por sua vez, a encontrar na ciência desenvolvida pela comunidade universitária o instrumento capaz de atender às aspirações coletivas.

Assim, o horizonte para a indissociabilidade Ensino/ Pesquisa/Extensão - EPE pode ser expresso como ação vinculada, contínua e processual de uma nova política, uma nova postura fomentando a parceria docência-serviço numa disposição para ultrapassar os limites da Universidade, propiciando um fluxo de troca de saberes sistematizados e favorecendo um trabalho interdisciplinar e, igualmente, fornecendo elementos para interpretação e transformação da realidade de saúde.

Essa disposição de integração, de parceria e de mudança, mais do que no plano do conhecimento, situa-se na práxis. Uma práxis, segundo Reis (1992), que tenha disposição para produzir conhecimento histórico inovador, voltado para a realidade de saúde da região e que seja objeto do ensino e suporte da prestação de serviços à comunidade.

A nosso ver, assumir essa disposição passa pela necessidade de articulação com os profissionais egressos no mercado de trabalho, aproximando e fortalecendo a tríade da indissociabilidade EPE através da estratégia de educação continuada em serviço.

Esse esforço requer uma reflexão crítica da formação básica profissional, das experiências acadêmicas oferecidas e a realidade profissional encontrada no mercado de trabalho, pois, como refere Faria (2000, p.02), "é o conhecimento quem controla o potencial criativo da humanidade nesta era de globalização. É ele que move o mundo em torno de uma economia do conhecimento".

Historicamente, a educação continuada, enquanto educação de adultos, tem sido relegada a um segundo plano.
Entretanto, este quadro vem se modificando face à necessidade de acompanhamento do individuo às transformações tecnológicas e sociais que vêm ocorrendo no mundo e no trabalho. A educação continuada em serviço, proporcionada através da parceria docência-serviço, precisa levar em consideração o saber adquirido pelo profissional nas experiências de trabalho. A valorização desse saber permite apontar com maior propriedade a realidade desse serviço, a expressão de suas necessidades e problemas, estimulando, no processo de educação continuada, a troca mútua de experiências, a criação de novo saber e nova prática, a partir da crítica e instrumentalização gerada pela vivência deste processo.

\section{CONSIDERAÇÕES FINAIS}

Tendo em vista estas reflexões, podemos perceber que a essência da formação profissional está na conscientização do indivíduo sobre seu papel enquanto cidadão. De posse desta consciência crítica, poderá ele instrumentalizar-se para melhor concretizar sua atuação junto à sua comunidade.

Sabidamente a Universidade é o terreno mais propício para a germinação de valores que remetam o indivíduo a este envolvimento com a sociedade. No entanto, parece estar havendo um certo distanciamento entre o aluno e a Universidade, após sua formação acadêmica. Esta lacuna dificulta o avanço do indivíduo, enquanto cidadão e profissional, pois ele vai desenvolver sua atividade profissional de forma isolada, muitas vezes, desvinculada da sua realidade. A Universidade, por sua vez, ao perder este contato com o aluno egresso, limita seu conhecimento no que se refere ao mercado de trabalho em que está inserido este egresso, impossibilitando o desenvolvimento de uma produção de conhecimento mais coerente com a realidade que o aluno irá encontrar após a conclusão do curso. Além disso, este distanciamento entre ambos acaba por tolher a participação da comunidade em geral, dos serviços desenvolvidos pela própria Universidade, tanto na perspectiva de usuária destes serviços, como na condição de "participante" ativa dos mesmos.

Particularmente, a nossa vivência junto ao GEPES e ao Projeto de Pesquisa intitulado "Projeto Parceria Docência-Serviços de Saúde: Uma Proposta de Educação Continuada" possibilitou-nos exercitar algumas considerações sobre o papel da Universidade na Educação Continuada dos alunos egressos. Este projeto, em especial, objetiva promover a Educação Continuada desenvolvendo a parceria entre a docência e os serviços de saúde, através do profissional egresso do Curso de Enfermagem da Universidade Federal de Santa Maria - RS. As constantes discussões ocorridas no grupo permitiram a formação de algumas expectativas no que se refere ao intercâmbio entre a Universidade/Alunos Egressos/Serviços de Saúde, que, acreditamos, poderiam auxiliar na superação de algumas lacunas existentes na formação profissional do aluno e, após, enquanto trabalhador.

Primeiramente, consideramos ser fundamental a inclusão de uma filosofia humanística na formação profissional, que $\mathrm{o}$ auxilie a refletir sobre seus próprios valores e ações e que o instrumentalize a buscar uma práxis crítica 
e transformadora. Aliado a isso, acreditamos que o fortalecimento da integração entre ensino, pesquisa e extensão possibilitaria um redimensionamento da produção de conhecimento gerida na Universidade e de suas ações junto à sociedade.

Outro fator que poderia contribuir para o fortalecimento do vínculo entre a Universidade e o aluno egresso é a formação de uma cultura institucional favorável à Educação Continuada, o que pode ter início através da sensibilização do seu quadro docente. A Universidade precisa estar aberta à política de qualificação docente, visto que os professores necessitam estar preparados para construir o conhecimento científico conjuntamente com os acadêmicos, incentivando-os ao desenvolvimento da ética e da cidadania, do trabalho em equipe, da participação em projetos, dentre outros.

A Universidade deve também divulgar intensamente os seus serviços junto à comunidade, assim como deve buscar, junto a esta, informações referenciais sobre as necessidades dessa comunidade. Entendemos que algumas formas de concretizar este vínculo se dão através da formação de Núcleo de Apoio ao Aluno Egresso e do fomento de parcerias entre Universidade/Alunos Egressos/Serviços de Saúde. O Núcleo atuaria como meio de manutenção do vínculo, minimizando um dos problemas comuns atualmente, que é a ruptura entre aluno e universidade no momento da conclusão do curso de graduação ou pós-graduação. A parceria enquanto projeto político institucional poderia motivar o aluno à Educação Continuada e contribuiria para a qualificação do ensino desenvolvido na Universidade, bem como possibilitaria sua valorização enquanto centro formador.

Por fim, entendemos que, concomitantemente ao desenvolvimento deste processo, deveria acontecer um trabalho de estímulo, junto às instituições, para torná-las mais receptivas à formação de parcerias com a Universidade e, por conseqüência, à educação continuada em si.

Em suma, podemos concluir quea Universidade deve implementar meios que venham concretizar mais objetivamente seu vínculo com os alunos egressos. Acreditamos que, através deste comprometimento com o homem e profissional em formação, a Universidade estará cumprindo seu papel junto à sociedade.

\section{REFERÊNCIAS BIBLIOGRÁFICAS}

BACKES, V. M. S. et al. A parceria docência e os serviços de saúde: uma proposta de educação continuada. UFSM/ FAPERGS, 2000. Relatório Teórico/Cientifico Pesquisa. 79p.

FARIA, D. S. Extensão Universitária na sociedade do conhecimento. Participação: Revista do Decanato de Extensão da Universidade de Brasília, Brasília, v. 7, jul. 2000. Edição especial.

FERNANDES, J. D. Indissociabilidade Ensino/Pesquisa/ Extensão: buscando a essência e engendrando o novo. Rev. Bras. de Enferm., Brasília, v. 47, n. 1, p.36-41, jan./mar. 1994.

FREIRE, P. Educação e mudança. 23. ed. Rio de Janeiro: Paz e Terra, 1999.

PENNA, L. de A. A universidade no Terceiro Milênio: a construção da dignidade humana. In: GONÇALVES,R. Propostas para uma universidade no terceiro milênio. Rio de Janeiro: Fujb, 1993.

REIS, R. N. A institucionalização da extensão. Educação Brasileira, Brasília, v. 14, n. 28, p. 67-81, 1992.

SANTOS, E.F. et al. Legislação de Enfermagem: atos normativos do exercício e do ensino de enfermagem. São Paulo: Atheneu, 1997.

TAVARES, M. das G. M. A indissociabilidade entre ensino, pesquisa e extensão: em busca da universidade cidadã. Participação: Revista do Decanato de Extensão da Universidade de Brasília, Brasília, v. 7, jul. 2000. Edição especial. 